\title{
Development of Powered Support Hydraulic Legs with Improved Performance
}

\author{
Gennady Buyalich ${ }^{1, *}$, Maxim Byakov ${ }^{2}$, Konstantin Buyalich ${ }^{1}$, and Egor Shtenin ${ }^{1}$ \\ ${ }^{1}$ T.F. Gorbachev Kuzbass State Technical University, 65000028 Vesennya st., Kemerovo, Russia \\ ${ }^{2}$ SUEK-Kuzbass, 652507 1, Vasilev street, Leninsk-Kuznetsky, Kemerovo region, Russia
}

\begin{abstract}
The paper gives a description of the technical solution for the design of a hydraulic leg piston for mechanized roof supports. This technical solution allows the sealing gap to remain almost constant in a wide range of pressures of the working fluid, while significantly improving the working conditions of the lip seal on the piston. This technical solution consists in the fact that, on the side of the piston cavity of the hydraulic leg, the piston contains a sleeve with a seal located on it, which under the action of the pressure of the working fluid deforms in the radial direction, compensating for an increase in the diameter of the working cylinder. In this case, the described technical solution is not subject to inertia and is able to work with static and with dynamic external loads on a hydraulic leg. The results of a comparative finite-element simulation of the stress-strain state of a hydraulic leg at the junction of the piston and the working cylinder are given for the $360 \mathrm{~mm}$ dia hydraulic leg of Glinik support with serial and proposed pistons. It is shown that with the proposed piston, when the pressure of the working fluid in the piston cavity is $62 \mathrm{MPa}$, the change in the radial sealing gap is less than 20 times compared with the serial design.
\end{abstract}

\section{Introduction}

Hydraulic legs are the main unit of powered roof supports, which take up pressure from rock pressure, and also ensure the functioning of the other coal mining machines of the system and safe working conditions for miners [1-3].

Hydraulic legs of powered supports are highly loaded with internal pressure of the working fluid, which varies from $32 \mathrm{MPa}$ (nominal working pressure in the hydraulic system of pumping stations) to $42-56 \mathrm{MPa}$ (nominal working pressure in the hydraulic system of hydraulic legs of modern powered supports corresponding to the pressure setting of the safety valve).

Under the action of such a high pressure, the diameter of the inner surface of the working cylinder increases with an increase in the gap between the piston and the cylinder, which complicates the operation of piston lip seals. The size of the sealed gap is proportional to the pressure of the working fluid and depends on the design dimensions of the working cylinder, leg extension [4-6] and the properties of the material from which the parts are made.

*Corresponding author: gdb@kuzstu.ru 


\section{Materials and Methods}

During the collapse of the main roof there are dynamic loads on the support and on the hydraulic system of the hydraulic legs, caused by the destruction of rock into the blocks, the size of which is determined by the physical and mechanical properties and thickness of the layers [7-9].

After brittle fracture, these blocks of the main roof move at a speed of up to $3.5 \mathrm{~m} / \mathrm{s}$ to the value of 0.1 to $50 \mathrm{~mm}$. At such high speeds of the piston of the hydraulic leg, the safety valve protecting its hydraulic system from critical pressures does not have time to work due to its inertia [7]. In addition, at such speeds of piston movement a large flow rate of fluid is formed through channels in the hydraulic block, communicating the piston cavity with the drain, which also contributes to overpressure above the working resistance.

To reduce the intensity of dynamic manifestations of rock pressure, special devices of the active type are used to support the face, which balance the distribution of the support resistance across the width of the supported space [10] or devices for adapting the support hydraulic system to the rock pressure level, as well as devices to reduce dynamic pressure surges in the piston cavity when the safety valve actuates $[11,12]$.

As KuzSTU studies have shown, the radial deformations of the working cylinder are proportional to the pressure of the working fluid and are determined by several factors, the main of which are the design parameters and properties of materials [4-6].

Lip seals in the piston group of the hydraulic leg are designed to seal the piston cavity and create a roof supporting effort in the powered support.

The lip seals operating under high pressure (the nominal working pressure in the hydraulic leg is about 42 to $56 \mathrm{MPa}$ ) are particularly sensitive to the size of the seal gap. Therefore, at maximum pressures of the working fluid, or, even worse, at pressure surges under dynamic external loads, the gap can exceed its critical value, at which the tightness is lost.

\section{Results and Discussion}

Modelling the behaviour of piston seals during reciprocating motion [13-15] shows that their sealing properties are determined by many factors [16], the main ones being the gap size, contact pressures during the sealing and assembly processes, and also on the design parameters of the sealing assembly [17-21].

In order to reduce the sealing gaps, it is possible to reduce the tolerance fields for the manufacture of parts in the piston-cylinder interface, however, this leads to an increase in manufacturing accuracy and, hence, to higher production costs [8].

To maintain constant sealing gaps in a wide range of pressures of the working fluid, the hydraulic leg design is proposed with an upgraded piston shown in Figures 1 and 2. The figures show working cylinder 1 with bottom 2 , rod 3 with piston 4 and nut 11 , on which lip seals 5 and 6 and guide polyurethane rings 7 and 8 are placed. The piston ends with sleeve 9 deformed under pressure of the liquid, its crumpling in the lower position is prevented by stop 10. Figure 1 shows the coupling of the piston with the working cylinder at zero pressure of the working fluid in the piston cavity of the leg, and Figure 2 shows it at nominal working pressure. 


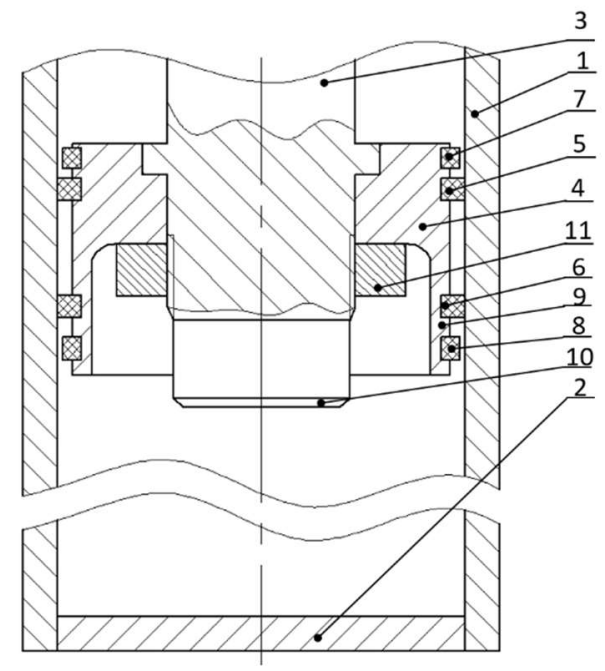

Fig. 1. Position of piston and cylinder at zero pressure.

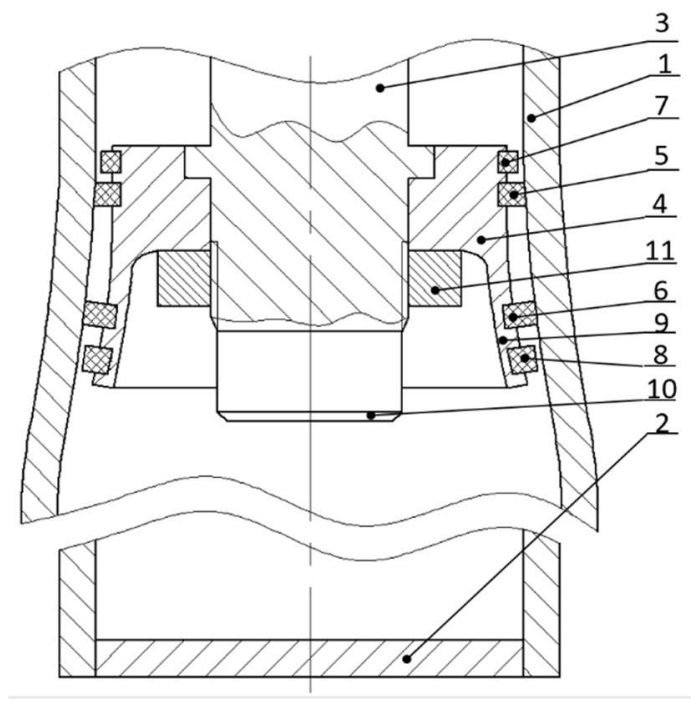

Fig. 2. Position of piston and cylinder at nominal pressure of working fluid.

Under the action of the working fluid pressure, the walls of the working cylinder are deformed in the radial direction, increasing the clearance relative to the piston. In this case, the piston bushing is also deformed in the radial direction under the action of the pressure of the working fluid, compensating for an increase in the diameter of the cylinder.

In addition, it should be noted that under the action of dynamic loads on the support from the collapsing rock $[14,18,19]$, this system has a higher speed of response compared to mechanical systems of similar purpose.

Calculation of deformations carried out for Glinik $360 \mathrm{~mm}$ dia hydraulic leg having a piston of the proposed design with $1 / 4$ extension of the maximum value has shown that the radial deformations of the working cylinder at the point of seal 6 (Fig. 1, 2) location are from 0.077 to $0.15 \mathrm{~mm}(0.154$ to $0.30 \mathrm{~mm}$ per diameter $)$ at pressures of the working fluid from 32 to $62 \mathrm{MPa}$ (see Fig. 3) respectively which exceeds the tolerance level for the manufacture of the "piston-working cylinder" interface. 


\section{Gap change at $1 / 4$ extension}

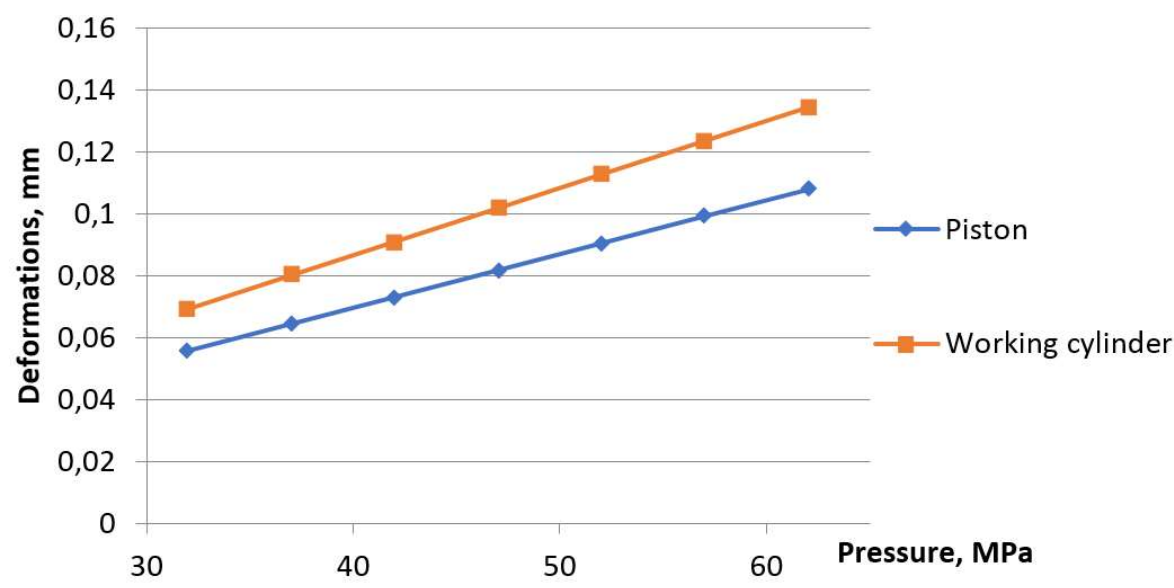

Fig. 3. Deformation of cylinder in selected points.

At similar pressure levels of the working fluid, the proposed piston design shows that the corresponding displacements of the starting point of the seal location have approximately the same values (Fig. 3) - from 0.074 to $0.144 \mathrm{~mm}$ by radius (from 0.15 to $0.29 \mathrm{~mm}$ by diameter).

The resulting value of the change in the sealing gap by radius is shown in Fig. 4 and ranges from $0.0032 \mathrm{~mm}$ at pressure of $32 \mathrm{MPa}$ to $0.0061 \mathrm{~mm}$ at pressure of $62 \mathrm{MPa}$, which is much less than the minimum value of the tolerance field of the "piston - working cylinder" interface.

\section{Gap change at $1 / 4$ extension}

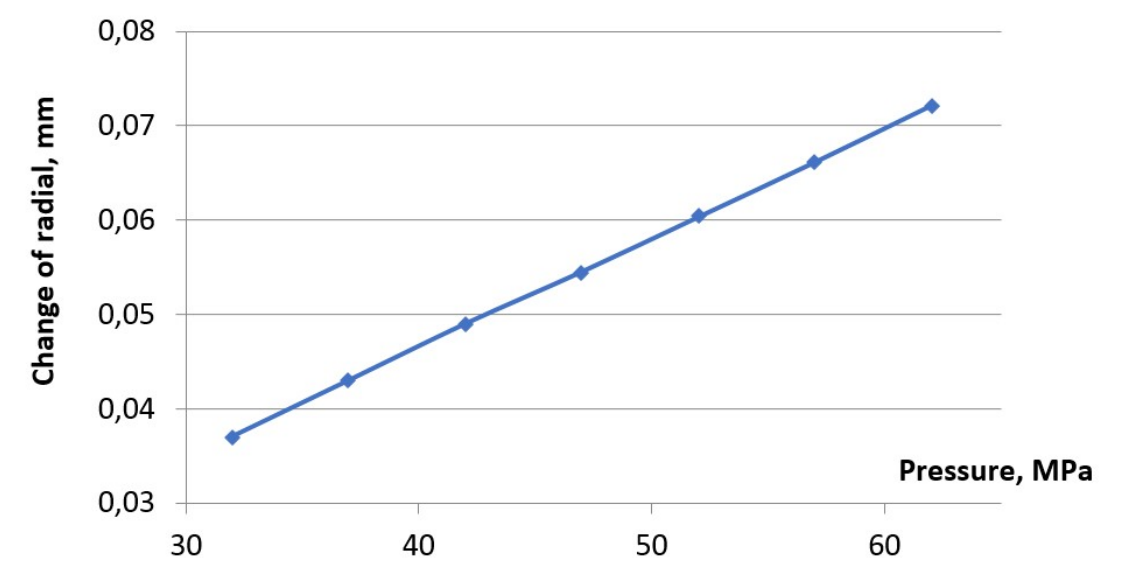

Fig. 4. Change of radial sealed gap at different pressure levels of hydraulic fluid.

Among other things, this design has a lower inertia in fast processes compared to safety valves, and the change in the sealing gap does not depend on the bore of the channels between the piston cavity and the drain. 


\section{Conclusion}

Thus, the proposed technical solution for making a piston with a deformable sleeve located on the side of the piston cavity allows you to automatically maintain a sealable gap within the specified limits in a wide range of operating pressures of the working fluid in both static and dynamic modes of external load application.

\section{References}

1. P. Novak, J. Babjak, 4th Coal Operators Conference, 34, 47 (2014)

2. J. C. Ralston, D. C. Reid, M. T. Dunn, D. W. Hainsworth, International Journal of Mining Science and Technology, 25:6, 865 (2015)

3. C. Umar, Behavior of shield support in longwall mining (National Institute of Technology, Rourkela, 2014)

4. G. D. Buyalich, K. G. Buyalich, V. V. Voyevodin, IOP Conf. Series: Materials Science and Engineering. - IOP Publishing, 127, 012034 (2016)

5. G. D. Buyalich, K. G. Buyalich, V. V. Voyevodin, IOP Conference Series: Materials Science and Engineering, 91, 012087 (2015)

6. G. Buyalich, K. Buyalich, M. Byakov, E3S Web Conf., 21, 22671242, (2017)

7. G. S. P. Singh, U. K. Singh, Mining Technology : IMM Transactions section A, 118:1, 47 (2009)

8. D. Szurgacz, J. Brodny, E3S Web Conf., 41, 03019 (2018)

9. D. Szurgacz, E3S Web Conf., 29, 00007 (2018)

10. G. D. Buyalich, B. A. Aleksandrov, Y. A. Antonov, V. V. Voyevodin, Journal of Mining Science, 6:5, 487 (2000)

11. V. V. Gabov, D. A. Zadkov, A. V. Stebnev, Eurasian Mining, 1, 37 (2016)

12. V. V. Buevich, V. V. Gabov, D. A. Zadkov, P. A Vasilieva, Eurasian Mining. TU Bergakademie Freiberg, Germany, 1:2, 11 (2015)

13. D. Szurgacz, J. Brodny, SGEM, 17:13, 781-788 (2017) DOI: 10.5593/sgem2017/13/S03.099

14. G. K. Nikas, Proceedings of the Institution of Mechanical Engineers, Part J: Journal of Engineering Tribology, 224:1, 1 (2008)

15. B. Yang, R. Salant, G. W. Woodruff, Sealing Technology, 11, 8 (2011)

16. G. Buyalich, M. Byakov, K. Buyalich, E3S Web Conf., 41, (2018)

17. A. Karaszkiewicz, Tribology International, 21:6, 361 (1988)

18. A. Karaszkiewicz, Industrial and Engineering Chemistry Research, 29:10, 2134 (1990)

19. G. K. Nikas, Fast performance-analysis of rectangular-rounded hydraulic reciprocating seals: Mathematical model and experimental validation at temperatures between -54 and $+135^{\circ} \mathrm{C}$ (Tribology International, London, 2018)

20. D. Szurgacz, J. Sust. Min., 14:4, 157-163 (2015) DOI: 10.1016/j.jsm.2015.12.001

21. S. J. Tomlinson, M. J. D. Fisher, T. Smith, K. Pascal, SAE Technical Papers, 34, 67 (2017) 